\title{
Randomization Plan
}

National Cancer Institute

\section{Source}

National Cancer Institute. Randomization Plan. NCI Thesaurus. Code C115778.

A proposed method that describes the details of the randomization method. 